
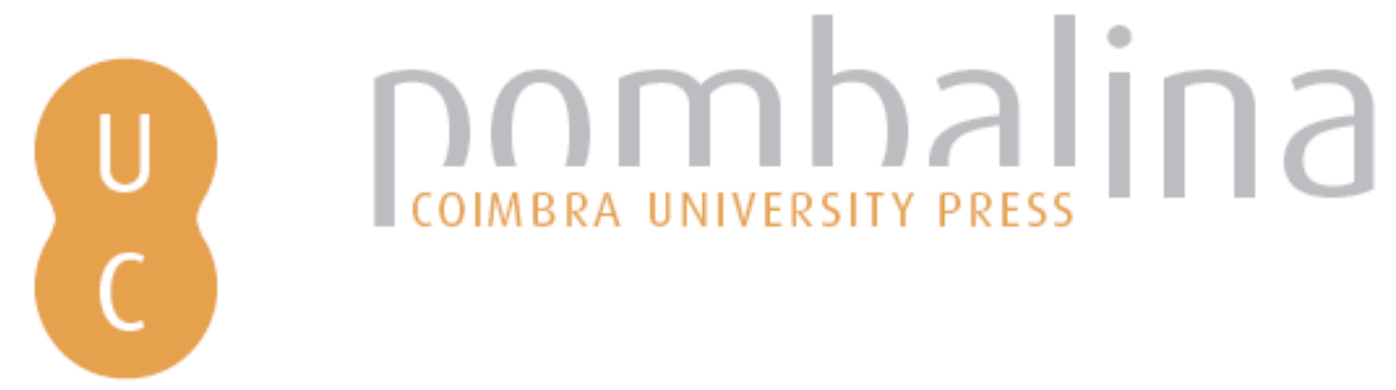

\title{
Maintenance continuous performance assessment of a hospital operating room AVAC system
}

\author{
Autor(es): $\quad$ Assis, Rui \\ Imprensa da Universidade de Coimbra; Faculdade de Ciências e \\ Publicado por: Tecnologia da Universidade de Coimbra, Departamento de Engenharia \\ Mecânica \\ URL
persistente: $\quad$ URI:http://hdl.handle.net/10316.2/33330 \\ DOI: $\quad$ DOI:http://dx.doi.org/10.14195/978-972-8954-42-0_18 \\ Accessed : $\quad$ 26-Apr-2023 14:31:05
}

A navegação consulta e descarregamento dos títulos inseridos nas Bibliotecas Digitais UC Digitalis, UC Pombalina e UC Impactum, pressupõem a aceitação plena e sem reservas dos Termos e Condições de Uso destas Bibliotecas Digitais, disponíveis em https://digitalis.uc.pt/pt-pt/termos.

Conforme exposto nos referidos Termos e Condições de Uso, o descarregamento de títulos de acesso restrito requer uma licença válida de autorização devendo o utilizador aceder ao(s) documento(s) a partir de um endereço de IP da instituição detentora da supramencionada licença.

Ao utilizador é apenas permitido o descarregamento para uso pessoal, pelo que o emprego do(s) título(s) descarregado(s) para outro fim, designadamente comercial, carece de autorização do respetivo autor ou editor da obra.

Na medida em que todas as obras da UC Digitalis se encontram protegidas pelo Código do Direito de Autor e Direitos Conexos e demais legislação aplicável, toda a cópia, parcial ou total, deste documento, nos casos em que é legalmente admitida, deverá conter ou fazer-se acompanhar por este aviso.

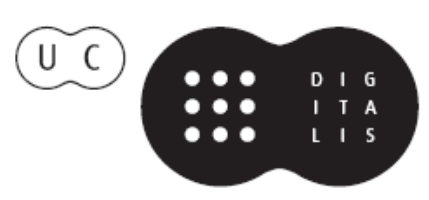




\title{
Maintenance Continuous Performance Assessment of a Hospital Operating Room AVAC System
}

\author{
Rui Assis \\ rassis@rassis.com; www.rassis.com \\ Instituto de Soldadura e Qualidade - ISQ \\ Tagus Park, Oeiras, Portugal
}

\begin{abstract}
The present paper depicts a method to continuously evaluate the operational performance of resources allocated to the maintenance of an AVAC system, that provides air conditioning to surgery rooms in a public hospital at the lowest possible energy cost. The method combines three other methods: the "Balance Score Card (BSC)", the "Analytical Hierarchy Process (AHP)" and the "Metrics-Merit Conversion (MMC)". The hierarchy is formed by 52 indicators. A sensitivity analysis completes the decision making process by providing guidance to prioritize improvement courses of action.
\end{abstract}

\section{Keywords-AHP, performance assessment, metrics}

\section{INTRODUCTION}

The recently published International Standard ISO 55000 specifies the requirements for the establishment, implementation, maintenance and improvement of a management system for asset management, referred to as an "asset management system". This International Standard can be applied to all types of assets and by all types and sizes of organizations. This International Standard is intended to be used for managing physical assets in particular, but it can also be applied to other asset types. Point 9 of this standard deals with "Performance evaluation" and sub-point 9.1, more specifically, deals with "Monitoring, measurement, analysis and evaluation".

Further below, a method which was developed a few years ago by the author and counting already with a few implementations in the field is proposed to allow the management performance assessment of resources - technical and human - allocated to a major objective here named "overall merit" in a broad sense. The method combines three known management methods: Balanced Scorecard (BSC) [2], Analytic Hierarchy Process (AHP) [3] and Metrics-Merit Conversion (MMC) [4]. The management performance (the overall merit) is designed in such a fashion that it is made dependent on a number of sub-objectives forming a multilevel hierarchy which is designed according to each specific case under evaluation.

This design must obey to two principles: 1) to be permanently in line with the strategic objectives of the Organization and 2) influence behaviours of people in charge (motivate), towards the accomplishment of each sub-objective measured by a specific "metric". Targets of the metrics are negotiated between a management controller ${ }^{1}$ and people in charge and fine-tuned during the course of time as improvements progress.

\section{BACKGROUND}

Most of the historical background of management performance control over the years since the end of the XIX century and the description of the three management methods used in this article can be found in reference [1] Chapter 8 . The author will focus from this point forward on the method that aggregates the three above mentioned methods with a real world case scenario (numerical data are altered for privacy protection purposes).

\section{THE CASE}

The case tackles an $R \& D$ project (that is still under way) promoted by the ISQ group with a partnership comprehending IST $^{2}$ and QUADRANTE. The project focus on the technical and organizational resources allocated to guarantee an appropriate air quality at the minimum energy cost possible in the operating rooms of a Portuguese public hospital. The same approach is expected to be replicated later on to other services.

Adequate air quality is understood to comply with standards and in house regulations, as well as to accommodate temperature and relative humidity set by the head surgeon (dependent on each specific surgery). These two variables, besides the fact of playing an important role with regard to ambient comfort, are also known to influence greatly the size of pathogenic microorganism's colonies.

The project promoter formed a working group (WG) and the author was nominated as technical coordinator.

Given the unique missions in health services providers, metrics cannot be developed alone by outside consultants. Metrics have to be carefully designed by those who know these processes most intimately - the hospital engineering and maintenance staff, from craft to management. Furthermore, people involved will feel more responsible and committed to achieving the goals (measured by metrics) that they have negotiated and accepted beforehand. Metrics also allow professionals to know how well their services are running and whether they conform to requirements they are engaged with. It

\footnotetext{
${ }^{1}$ With appropriate soft skills and experience

2 Instituto Superior Técnico
} 
is the role of the WG to provide guidance to these professionals through the several steps of the method.

\section{Step 1: Hierarchy design}

Having in mind the second perspective of BSC "Business Process", which refers to internal business processes and after a in depth diagnosis, the WG identified three main objectives to be continuously monitored:

1. "Quality" of the air in the rooms and maintenance services provided to the AVAC equipment. In fact, this is the main objective. The diagnosis revealed several spots where parameters were out of standard;

2. "Efficiency"; resources have to be effective (providing good air quality) and efficient simultaneously, that is, provide good air quality at the minimum possible economic cost. A computer simulation revealed a few issues to be corrected or updated in face of the current state of the art;

3. "Availability" of the AVAC equipment. In fact, good air quality is necessary all the time, which means that the "twenty four seven" regimen of service has to be guaranteed. This can be accomplished by increasing reliability in different forms. The diagnosis revealed a poor information system in the Maintenance Department supported on several dispersed Excel Worksheets.

In order to better describe which is meant by each one of these three objectives, the WG, after hours of discussion, identified a number of sub-objectives contributing to those three upper level objectives (depicted through Figures 1 to 3).

In Figures 1, 2 and 3, objectives are highlighted in grey, metrics are bordered and references can be seen in between.

Metrics have to be chosen very carefully in order to measure as effectively and accurately as possible the progress made over time towards the achievement of each negotiated target. Data on metrics originated over the past few months are gathered in a data warehouse and can be accessed at any time.

Some of these data are refreshed automatically on a timely basis (every \# minutes) which is the case of physical variables (temperatures, humidity, pressure,...) governed by the existing $\mathrm{SCADA}^{3}$ while other data are driven by events, which is the case of closing work orders in a CMMS ${ }^{4}$. Some data are originated only when an audit takes place, which is the case of anesthetic gases concentrations, being therefore registered on purpose by hand.

Figure 1 depicts the hierarchy of sub-objectives necessary to pursuit in order to comply with the main objective "Quality". This objective contributes in turn, along with Efficiency and Availability, for the utmost merit (overall performance). A few notes on this particular hierarchy follow:

1. Physical metrics, such as temperature, are obtained in real time and are assessed by three characteristics (or metrics) which are:

\footnotetext{
${ }^{3}$ Supervisory Control And Data Acquisition

4 Computerized Maintenance Management System
}

a. "Frequency" of drifts from the preset values (upper and/or lower limits) which can be measured in drifts per hour (or any other period), and must be as close to zero as possible;

b. "Severity" of drifts which is divided into two parts: "Duration" which can be measured in minutes per drift, and "Magnitude" which can be measured by the percentile 90 of the amplitude frequency distribution of drifts. Both must be as close to zero as possible.

2. Metrics are calculated, or averaged, inside a time frame. In a three shift regimen, a time frame of 8 hours is often the most convenient;

3. With regard to temperature and relative humidity - two variables set by the head surgeon -, a time delay of 15 minutes had to be arranged in order to avoid readings during transient periods which would give rise to a misleading interpretation. Only stationary periods count;

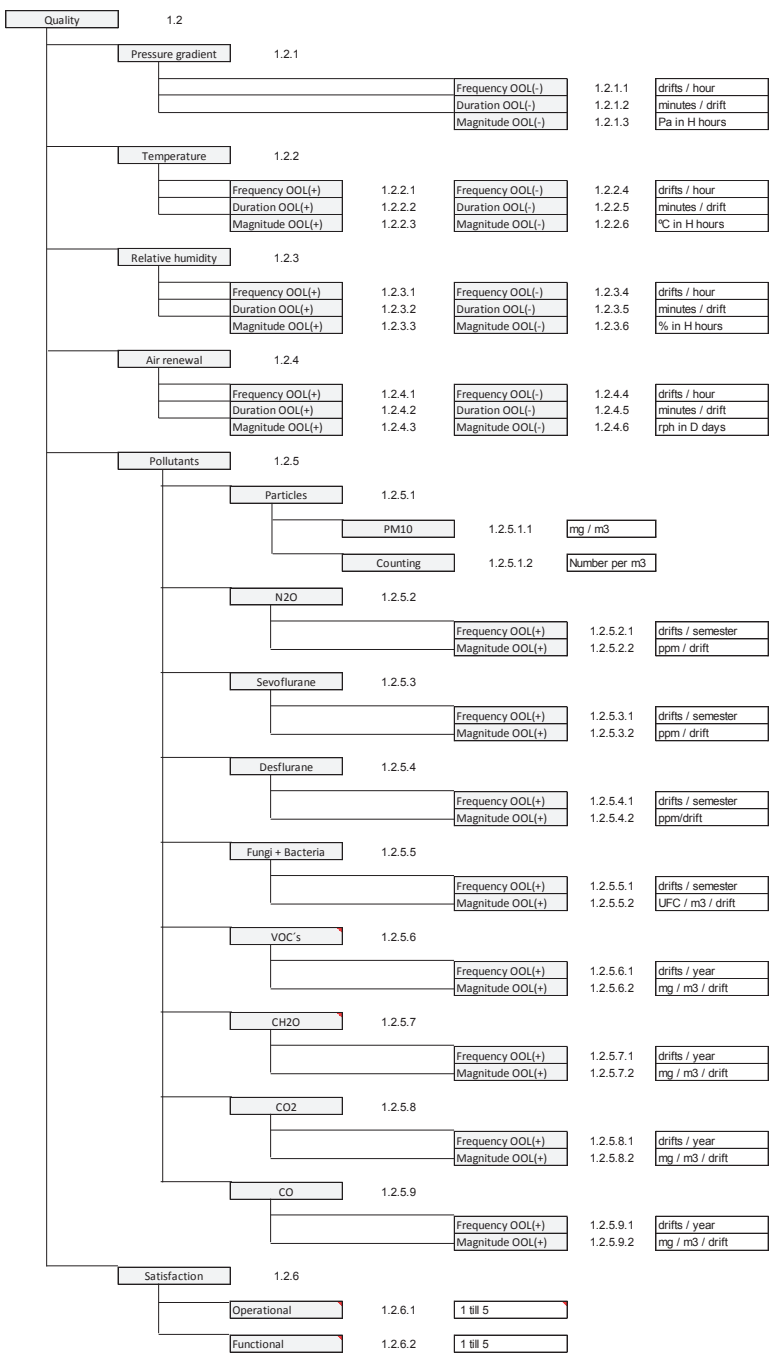

Fig. 1. Hierarchy of sub-objectives aiming to Quality 


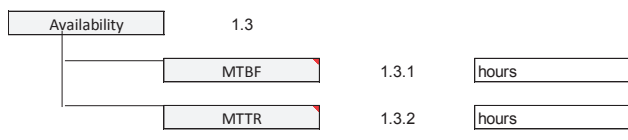

Fig. 2. Hierarchy of sub-objectives aiming to $\underline{\text { Availability }}$

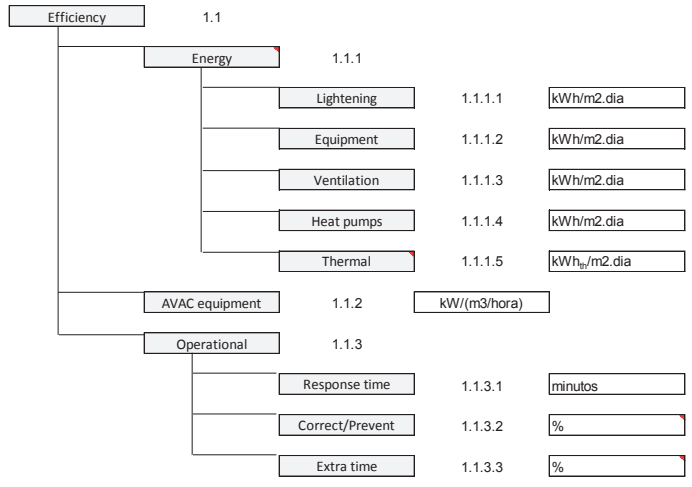

Fig. 3. Hierarchy of sub-objectives aiming to Efficiency

4. Metrics "Pressure gradient" and "Air renewals" (hourly number of) in each room are preferably measured in real time by adequate sensors instead of audits performed arbitrarily;

5. Pollutants have to be measured periodically as a routine or whenever there is a suspicion of a durable drift state. However, as concentrations of a few gases can be currently measured in real time by appropriate sensors, their adoption is highly recommended;

6. The degree of satisfaction is obtained twofold:

a. Through work orders related to AVAC that are being closed, by providing a specific field for the person who requested the work to enter his judgment on how well the work was done, within a scale from 1 to 5 ;

b. Through a questionnaire to be fulfilled every month by the people in charge of Services using also a scale ranging from 1 to 5 .

Figure 2 shows that "Availability" depends on "Reliability" or MTBF (Mean Time Between Failures) measured by the metric "hour" and "Maintainability" or MTTR (Mean Time To Repair) also measured in hours.

Figure 3 shows that "Efficiency" has two dimensions: one is "technical" (Electric energy and thermal energy) and the other is "operational", meaning that the former depends on equipment and the later depends on people (maintainers), that is, depends on how well the Maintenance Service is organized and competences held.

\section{STEP 2: HIERARCHY LEVEL WEIGHING}

Every objective in the hierarchy receives a weight proportional to the importance (preference) attributed by the WG. In this regard, the AHP methodology of pairwise comparison of objectives at each level of the hierarchy was used. The response to each question takes the form of a value from one to nine and its reciprocals. The magnitude of the response indicates the strength of preference of one decision element to another. Saaty [3] suggested numbers to express degrees of preference between elements $\mathrm{x}$ and $\mathrm{y}$ as can be seen in Table I.

TABLE I. SCALE OF PREFERENCES ACCORDING TO AHP

\begin{tabular}{|l|c|}
\hline \multicolumn{1}{|c|}{ If $\boldsymbol{x}$ is ... as (than) $\boldsymbol{y}}$, & $\begin{array}{c}\text {...then the preference } \\
\text { number to assign is: }\end{array}$ \\
\hline . Equally important/prefered & $\mathbf{1}$ \\
. Weakly more important/prefered & $\mathbf{3}$ \\
Strongly more important/prefered & $\mathbf{5}$ \\
. Very strongly more important/prefered & 7 \\
Absolutely more important/prefered & $\mathbf{9}$ \\
\hline
\end{tabular}

The pairwise comparison is quite advantageous when seeking to minimize the subjectivity always present in this type of decision making processes.

Table II depicts the result of the pairwise comparison of the five sub-objectives of the third level objective "Energy (efficiency)" leading to a Consistency Ratio of 0.069 (a threshold of 0.1 is actually considered) and the weights obtained which can be seen in the right extreme column.

TABLE II. PAIRWISE COMPARISON OF OBJECTIVES LOCATED IN LEVEL THREE

\begin{tabular}{|c|c|c|c|c|c|c|}
\hline \multicolumn{7}{|c|}{ Pairwise comparison of objectives } \\
\hline Criteria or Objectives & Lightening & Equipment & Ventilation & Heat pumps & Thermal & Weights \\
\hline Lightening & 1 & 2 & 3 & 1 & & 0,19091033 \\
\hline Equipment & & 1 & 1 & & & 0,09587115 \\
\hline Ventilation & & & 1 & & & 0,11050049 \\
\hline Heat pumps & & 3 & 2 & 1 & & 0,19558466 \\
\hline Thermal & 4 & 3 & 2 & 3 & 1 & 0,40713338 \\
\hline
\end{tabular}

The same approach was extended to all branches of the hierarchy of objectives.

\section{STEP 3: CONVERTING METRICS INTO MERIT SCORES}

Last readings of the elected metrics are depicted in Table III.

TABLE III. MOST RECENT METRIC VALUES OBTAINED

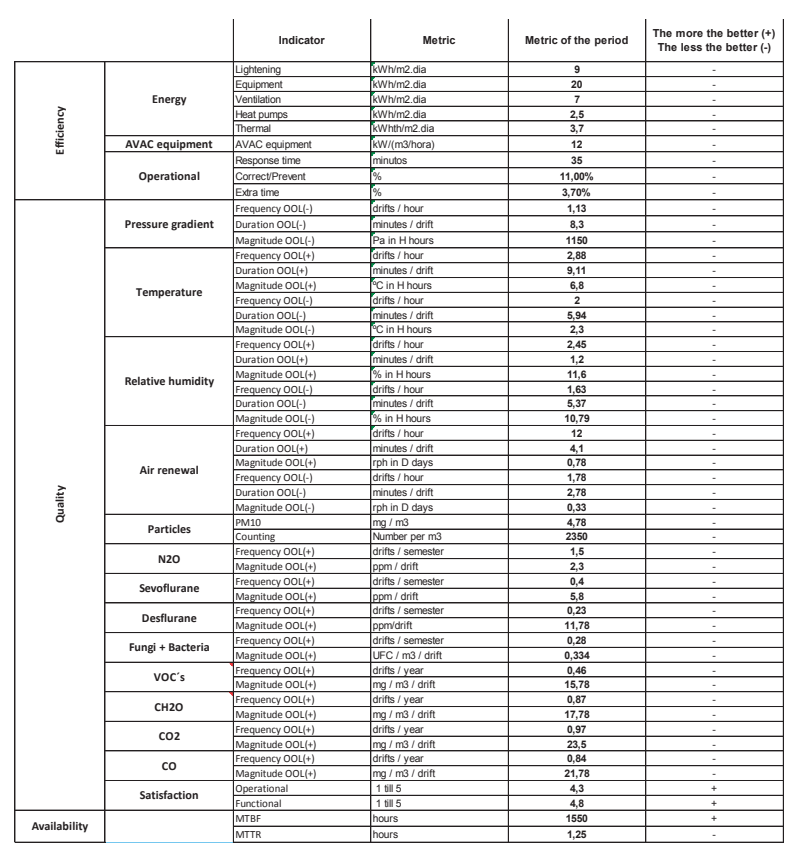


The ultimate goal is to achieve the maximum score of a non -dimensional scale which can be arbitrarily set as ranging from zero to whatever limit. The present case adopted a scale ranging from 0 to 10 . Zero (0) is given to a specific value of a metric which has already been registered in the recent past and has a low probability of being registered again. Ten (10) is attributed to a specific value of a metric which is believed to be attained in the near future (within a few weeks or months ahead), requiring management effort only, and is to be negotiated with the person who is responsible for its pursuit. The negotiation process is very important at this stage, as this is actually the more effective way of clearing doubts and gaining trust and commitment from people in charge.

The negotiation can be carried out by a future management controller acting preferably as a facilitator.

Once the value of a metric reaches the previously agreed upper level limit (equivalent to 10 in the merit scale), a new limit has to be agreed on. This is actually a short term commitment.

The method might be used to reward employees somehow.

Only two more metric values are set during an interactive process of judgment of level of effort needed to progress from 0 to 10 by dividing the metric range into quarters and choosing the $1^{\text {st }}$ quarter and the $3^{\text {rd }}$ quarter. The function that relates metric values to merit values can be linear or diverse. Most often two circumstances occur:

1. The situation is in such a bad state that little effort is required to start improving it. The merit gradient should therefore be small to start with and increase as performance progresses rewarding the augmentation of effort needed (as the situation becomes better, extra improvement becomes more and more difficult);

2. Resistance to change may happen. In these circumstances, the merit gradient is high to start with and diminishes as performance progresses. That is, a great effort is necessary at the beginning of the metric scale and becomes less and less demanding as it approaches the negotiated target. It may happen though the opposite towards the end of the merit scale and extra improvements require more and more effort. An increasing merit gradient is therefore applied.

Intermediate values of the function Merit $=f($ Metric $)$ can be approximated by a third degree polynomial function. Figures 4 and 5 depict an example of both situations.

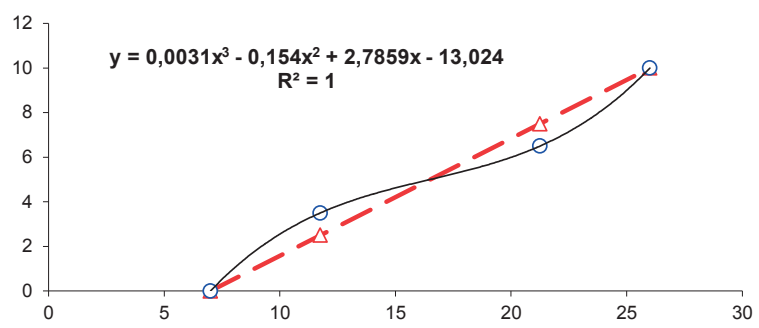

Fig. 4. Metric-Merit function when metric values are desirably ascendent

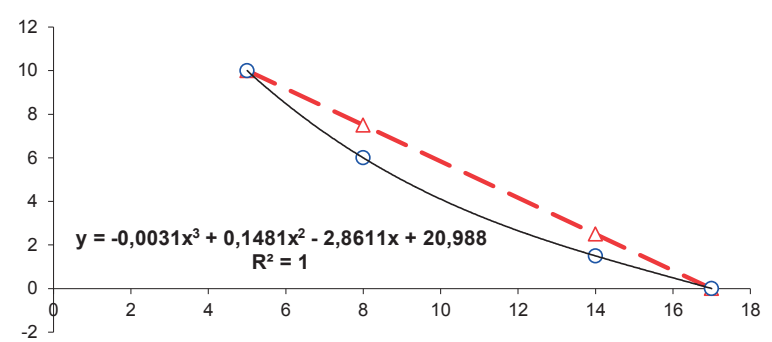

Fig. 5. Metric-Merit function when metric values are desirably descendent

EXCEL or MATLAB deal easily with this situation.

\section{STEP 4: OVERALL PERFORMANCE OR MANAGEMENT MERIT}

By multiplying merits of objectives at each level of the hierarchy by the correspondent weights of all upper levels in ascending order, an overall value of merit (score) is finally obtained. In the present case, a score of 6.57 is achieved within the preset scale ranging from 0 to 1 , which could be classified as "fairly good" if a semantic scale was used instead.

So, now what should be done in order to improve further this overall score (merit)?

\section{STEP 5: SENSITIVITY ANALYSIS}

To answer this question, one should perform a sensitivity analysis. This analysis consists of running a test to find out how much the overall score would increase if a metric is improved by a fixed percentage while keeping all the other metrics constant. The outcome of this process might then be arranged in descendant order and be displayed in a graph. This is the well-known Pareto analysis.

Based on data obtained through the four previous steps, an increase of $20 \%$ of each metric was supposed to be achieved. The graph in Figure 6 depicts the analysis outcome.

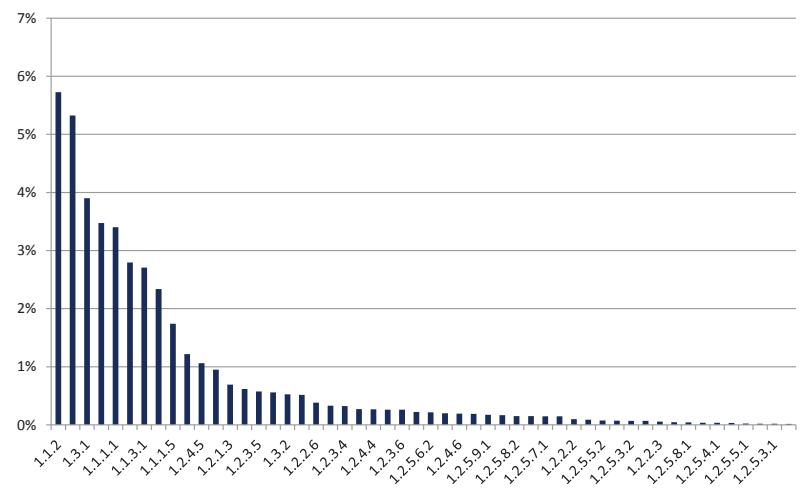

Fig. 6. Percentages of improvement of overall performance when each metric is supposed to be improved by $20 \%$

The graph clearly shows that objective reference 1.1 .2 presents the best return on management effort $(5.73 \%)$ followed by references 1.1.1.4 (5.32\%), 1.3.1 (3.90\%) and so on. If an investment is needed to allow future improvements, a 
cost-benefit analysis must be carried out before setting new targets.

\section{CONCLUSIONS}

A method combining three other popular methods in management (BSC, AHP and MMC) was applied to assess management performance on a timely basis of AVAC equipment allocated to a surgery room of a public Hospital.

Based on the second phase of BSC, a multilevel hierarchy of operational and technical objectives was designed to comply with strategic objectives of the Hospital. These objectives were weighted at each level of the hierarchy using the pairwise comparison advocated by AHP.

Metrics were chosen to enable the measurement of objectives in the most effective way possible. A minimum limit and a maximum limit of each metric, believed to be reached in the short run, were then negotiated with the people in charge.

For calculation purposes, metrics were then converted to a non-dimensional scale of arbitrary length depending on effort needed (or the merit that is supposed to reward it). In the exemplified case it was chosen to vary between 0 and 10 .

A multiplication of all these merit values by their correspondent weights through the hierarchy in ascending order allows reaching an overall merit value (also ranging from 0 to $10)$.

In the end, a sensitivity analysis allows tempering management effort by arranging in descendent order all the 52 metrics based on their actual gain contribution to the overall performance (or merit at the highest level of the hierarchy).
In short, a hierarchy of objectives were designed in such a way that the alignment with strategic objectives of the Organization is assured and a permanent negotiation of quantitative targets - made easy to monitor by practitioners themselves - actually encourages the development of a sense of responsibility and real commitment. Everyone knows where they are at any moment and where they are expected to be in the short run - this is exactly what we were aiming at.

The method can easily be used to reward performance with a pecuniary prize or any other form for that matter.

The method is intended to be replicated on two other services in the same hospital, in the context of the same project.

Scorecards built with the same methodology and applied to different services of the same organization, can be merged in order to provide management with a broader perspective on technical and operational maintenance performance of a health - or any other - facility.

\section{REFERENCES}

[1] Assis, Rui, Apoio à Decisão em Manutenção na Gestão de Activos Físicos, $2^{\text {nd }}$ edition, LIDEL, 2014

[2] Kaplan, Robert S. e David P. Norton, Balanced ScoreCard, Harvard Business School Press, Boston, 1996

[3] Saaty, Thomas L., Decision Making for Leaders: The Analytic Hierarchy Process for Decisions in a Complex World, RWS Publications, 2012

[4] Sink, Scott, e Thomas Tuttle, Planning and Measurement in your Organization of the Future, Industrial Engineering e Management Press, 1989 